\title{
CARTAS DE IAPAM: UM PERFIL DOS JAPONESES PELA ÓTICA DOS PORTUGUESES
}

Tae Suzuki

\section{Introdução}

Nos fins do século $X V$, início do $X V I$, Portugal e Japão se encontram pela primeira vez nas costas da China, através de seus mercadores. De um lado, Portugal que já tinha conquistado o mercado de especiarias da Índia, avançava rumo ao Oriente, tendo atingido o sul da China onde buscava novas bases para sua política mercantilista. De outro, o Japão que passava por uma fase de grandes conturbações internas e permitia a proliferação de piratas mercadores que, incentivados pelos senhores feudais do sul do país, infestavam a península coreana e o sul da China.

Informações trocadas pelos cais permitiram aos portugueses tomarem conhecimento da existência do Japão. Sua descoberta era apenas uma questão de tempo e ela se dá, ao acaso, quando uma nau portuguesa chega à ilha Tanegashima ao se desviar de sua rota para escapar de uma violenta tempestade, no ano de 1543. ${ }^{1}$

Mundos desconhecidos se defrontam. Nasce a curiosidade e com ela, a necessidade de um mútuo conhecimento e reconhecimento, notadamente para os portugueses que seguiam a política de expansionismo mercantilista, da qual a cristianização constituía um dos baluartes.

Inicia-se o trabalho de catequização do Japão pelos jesuítas, que tinham obtido da igreja católica o monopólio do Oriente. Nos quase cem anos de seus trabalhos em terras japonesas, várias foram as cartas e os relatos que os missionários enviaram aos superiores da Europa e da Índia, onde já havia sido criado um Padroado, bem como a outros companheiros no Oriente e no próprio Japão. Este trabalho se propõe a apresentar uma leitura do perfil do homem japonês traçado pelos jesuítas nessas cartas, que foram compiladas em 1598, pela Companhia de Jesus, em dois volumes: "Cartas que os Padres e Irmãos da Companhia de lesus escreueram dos Reynos de lapão \& China aos da mesma Companhia da India, \& Europa, desde anno de 1549 atè o de 1580" e "Segunda Parte das cartas de lapão que es- 
creuerão os padres, \& irmãos da Companhia de IESVS" São perfis que se distinguem pelas três fases da cristianização do Japão: 1 - da entrada e implantação do cristianismo (fins da década de $40 \sim$ década de 60), 2 de sua propagação (décadas de 60 a 80 ) e, 3 de sua perseguição (fins da década de 80 a início do século XVII).

\section{Primeira Fase: implantação do cristianismo}

Quando se fala dos primeiros relatos dos portugueses sobre o Japão e seu povo, não se pode esquecer da figura de um japonês conhecido apenas por Yajirô. Em 1545, por um crime que cometera em sua terra, ele se refugia, para escapar da justiça, em um templo em Kagoshima. Lá conhece o capitão Alvaro Vaz que, na impossibilidade de partir do Japão, apresenta Yajirô a Jorge Alvarez para que o leve em seu navio à Índia. Durante a viagem, o japonês ouve a história da vida do Padre Francisco Xavier e mostra grande interesse em se tornar cristão, sendo-lhe recomendado que procure pelo padre em Malaca.

Francisco Xavier, por outro lado, se encontrava em missão pela Índia e China, sentindo-se um pouco desiludido pelas dificuldades que enfrentava em seu trabalho de catequização e pelos poucos resultados que dele vinha obtendo. Apesar de já terem se passado cerca de dois anos desde a chegada dos portugueses a Tanegashima, Xavier ainda não tinha conhecimento do fato e nutria fortes desejos de conquistar o Japão, de que apenas ouvira falar, para lá propagar a fé cristã.

Sua ansiedade só aumenta quando conhece Yajirô em Malaca, em 1546, após quase um ano de desencontros. Xavier se impressiona, sobretudo, com a sede de conhecimento demonstrada por Yajirô, sempre indagando das coisas do cristianismo e da Europa, como também com sua facilidade em assimilar novos ensinamentos. A partir de uma única pessoa, o padre forma a primeira imagem do homem japonês: "gente de muito juyzo \& curiosa de saber, assi nas cousas de Deos, como na cousas da sciencia" (Francisco Xavier, Goa, 1549)2.

Essa imagem é reforçada pelas palavras de Yajirô que, ao ser indagado das possibilidades de se cristianizar o Japão, responde que "os japoneses não devem, de imediato, se tornar cristãos, devem primeiro fazer muitas perguntas. Depois devem se certificar de minhas respostas e de meu conhecimento e, acima de tudo, observar se minhas atitudes estão de acordo com o que prego. Após as discussões, se eu conseguir dar respostas satisfatórias e nada houver de reprovável em minhas ações e atitudes... prova- 
velmente, a começar do rei, os fidalgos e pessoas de bom discernimento, deverão seguir a fides (sic) de Cristo."3

A conviç̧ão de Xavier de que o Japão seria um ótimo lugar para se implantar e propagar o cristianismo leva-o a trabalhar no sentido de se obter a permissão em criar um Padroado no Japão. No entanto, ele parte de Goa antes mesmo de obtê-la, chegando a Kagoshima em agosto de 1549. A carta que envia aos padres de Goa, três meses após sua chegada ao Japão, revela ao Ocidente uma imagem do japonês como uma "gente que ategora temos conversado, he a melhor que ategora está descuberta, \& me parece que antre gente infiel não se achará outra q̃ ganhe aos lapões. He gẽte de mui boa couersação, geralmente boa, e não maliciosa: gente de hõra muito á maravilha, e estimão mais a honra, que nenhũa outra cousa. He gẽte pobre em geral, \& a pobreza antre os fidalgos, \& antre os que o não sam, não a tẽ por afronta(...) De maneira que mais estimão a hõra q̃ as riquezas. $\mathrm{He}$ gente de muitas cortesias hũs com outros. (...) He gẽte que não sofre injurias nenhũas, nem palavras ditas com desprezo. (...) todos os fidalgos se prezão muito de seruir ao senhor de terra, \& sam mui sojeitos a elle. (...) He gẽte sobria no comer, ainda que no beber são algum tanto largo. (...) São homẽs q̃ nunca jogão, porque lhes parece q̃ he grande deshöra. (...) He gente de mui boa vontade, mui couversavel, \& mui desejosa de saber (...) folgão de ouuir cousas conforme a razão."

Essa imagem vem ao encontro das aspirações de Xavier em criar o Padroado e dar início ao trabalho de catequização no Japão. Com tais características, nenhum outro povo melhor para absorver novos pensamentos - no caso, cristãos - e assim auxiliar a implantação do cristianismo no Japão, abrindo nova frente de expansão no Oriente.

Xavier enviou muitos outros relatos durante os três anos que passou no Japão e suas observações, sempre pautadas nos preceitos morais e religiosos do cristianismo, veiculam a forte conviç̧ão de que ali se encontrava um melhor lugar para desenvolver seu trabalho do que aquele realizado na Índia e na China. Seus relatos não poupam elogios às qualidades dos japoneses e quando tece críticas, é no sentido de apontar as diferenças de costumes para os quais os missionários deveriam atentar no seu mister. A preocupação em preservar e respeitar os usos, costumes e caráter do nativo é uma constante em Xavier e, ao introduzir o cristianismo no Japão, não deixa de impor essa sua marca nos trabalhos dos pósteros.

É condescendente com o povo e o japonês continua sendo cortês e educado (e, portanto, não receberiam os missionários como inimigos), de muito engenho e memória (aprenderiam rápido as oraçōes e as coisas de 
Deus), um povo de moral alta que preza a honra mais que a pobreza, respeitando sempre os grandes (com sua servilidade, estariam aptos a respeitar e servir a Deus).

É mais contundente no seus ataques aos bonzos, seus inimigos fidagais. Diz ele: "Menos peccado acho nos seculares, \& mais obedientes os vejo à razão, do que sam os que elles tem por padres, \& sacerdotes, que elles chamão Bonzos. (...) os leygos viuem melhor em seu estado, do que viuem os Bonzos no seu (...) Hay muitos erros \& males antre estes Bonzos, \& os que mais sabem os tem mayores." Critica suas condutas, principalmente do ponto de vista moral, pois "praticam vicios contra a natureza" e Ihes atribui toda a responsabilidade pela prática de maus costumes no povo, por terem incentivado com seu próprio exemplo, não só o homossexualismo, como também 0 aborto que as monjas, na verdade proibidas de manterem relações com os homens, praticavam por causa dos filhos concebidos em seus encontros clandestinos com os bonzos.

\section{Segunda Fase: propagação do cristianismo}

Depois de obtida a autorização para a atuação da Companhia de Jesus, no Japão, a cristianização se desenvolve rapidamente pelo sul do país até a capital. Os jesuítas dedicavam grande empenho na conversão dos senhores feudais que propiciava uma grande conquista numérica de cristãos, em razão da servilidade dos japoneses que acompanhavam seus amos. Cumpre notar o apoio conseguido junto a Nobunaga Oda, daimio que inicia o trabalho de unificação do país a partir da região de Owari e com facilidade em aceitar costumes estrangeiros, que se serviu da igreja católica para combater os bonzos da seita Honganji que Ihe faziam oposição. As dificuldades de trabalho, impostas pelo reduzido número de missionários e do elevado número de convertidos para atender, impunham a necessidade de uma propaganda dos trabalhos desenvolvidos pelos jesuítas no Japão, a fim de obterem auxílios da Coroa e da Companhia de Jesus, na Europa.

Os japoneses se refletem a seus olhos como homens corteses, bem civilizados e honrados, trabalhadores e inteligentes, curiosos e prudentes. No entanto, junto com os relatos de quão valiosas conquistas tinham conseguido, notadamente entre os fidalgos senhores de terra, já se nota nesta fase, mais acentuadamente na década de 80 , um distanciamento nas observações dos padres jesuítas que começam a se referir com menos paixão às características dos japoneses. 
São ainda muito condescendentes com este povo cortês e educado que bastou um Irmão começar a falar para sossegar uma multidão irriquieta de "dez a quinze mil pessoas que parecia nam estar alli ninguem" (Luis Fróis, 1582), "tẽ... tanta abilidade, \& memoria q [pregam] com muita facilidade cõ muito pouco de prática como os nossos de muitos annos" (Lourenço Messia, 1581), como os meninos do Seminário que "aprendem em tres quatro meses o que um menino nosso aprende em tres anos" (Luis Fróis, 1584), comedidos nas paixões sendo "rotos no silencio" (id.), mostrando "grandissimo freo na gula, \& na colera, \& ira exterior...\& por mor agastamento que tenha o pai do filho, ou o marido da molher, ou o inimigo do inimigo, de nenhũa maneira tho ha de mostrar, porque tem por baixeza verem desordem na gula, ou da ira no homem" (Lourenço Messia, 1584). No entanto, toda a prudência e cautela começam a ser vistos como "dissimulação de sentimento" (L. Fróis, 1584) que esconde e camufla a verdadeira intenção dos japoneses que são de "mui pouca fidelidade e menos amizade" (L. Fróis, 1586), principalmente em se tratando de guerras e disputas quando "por seus interesses cometem facilmente traições" (Gaspar Coelho, 1582). É-lhes difícil compreender e aceitar a barbárie como a do filho de Nobunaga que "temendose... que os tres fidalgos de sua corte que tinhão dado refens a Faxibandono [nome com que os portugueses denominavam Hideyoshi Toyotomi, daimio que tomou o lugar de Nobunaga na tarefa de unificação do país] ...não quisessem consentir no alevantamento Ihes deu conforme ao costume de lapão hum esplendido bãquete, \& no tempo da maior recreação Ihe mandou a todos tres cortar as cabeças" (L. Fróis, 1584).

Tornam-se mais frequentes as considerações sobre a crueldade e a frieza dos gentios que "por cousa pequena matam gente como a porcos... cortando o corpo e a cabeça em dois" (Alessandro Valignano, 1583) ou que "por ira ou por não se render ao inimigo, facilmente cortam a propria barriga" (id.), ou ainda, "mandou matar no mesmo dia todos os capitaes de que ao diante podia ter sospeita de pouca fidelidade" (L. Frois, 1581).

\section{Terceira Fase: perseguição do cristianismo}

Em 1582 morre Nobunaga Oda, sendo substituido por Hideyoshi Toyotomi no trabalho de unificação nacional. Seguindo seu antecessor, Hideyoshi foi, de início, um grande protetor do cristianismo cedendo, inclusive, terras para a construção de novas igrejas. Em 1587, entretanto, ao realizar uma viagem a Hakata e, após receber o Vice-provincial Gaspar Coelho, a quem até promete a cessão de um terreno para a lgreja, inesperadamente baixa uma ordem de expulsão dos jesuítas e decreta o exílio de Ukon Taka- 
yama, daimio cristão que ao ser chamado por Hideyoshi para renegar a nova religião, se nega a fazêlo.

Tem, então, início a fase de perseguição ao cristianismo que, enquanto Hideyoshi é vivo (até 1598), fica apenas no papel graças, inclusive, às intervenções do Padre Visitador Valignano e do Vice-provincial Gaspar Coelho junto a Hideyoshi, então Primeiro-ministro. A perseguição ganha fôlego com a criação do xogunato Tokugawa (1603) por leyasu que, à medida que ia perfazendo sua política isolacionista, reinicia a perseguição ao cristianismo. O xogunato promulga uma série de editos: proíbe o cristianismo em terras de domínio direto do xogunato (1612), proíbe o cristianismo e expulsa os cristãos de todo o território japonês (1613) e, mesmo após a morte de leyasu (1616), continua, decretando a ordem oficial de proibição pelo xogunato (1618), baixando uma ordem aos daimios para proibirem o cristianismo em suas terras (1639), terminando com a proibição final anunciada em praças públicas através dos kôsatu (placas de madeira colocadas em praças para fazerem o povo conhecedor das ordens governamentais), no ano de 1654.

Aquele Hideyoshi que "não somente he [era] contrario as cousas de Deos, mas em o que mostra estima em muito nossa santa lei, \& a tem por mais verdadeira que as enganosas seitas dos Bonzos" (L. Fróis, 1584), homem "de astucia e prudencia... bravo nas lutas" (id.), que "nunca Ihe [Madalena, dama convertida] tocou com a mão, nem a ella, nem a sua filha, nem Ihe falou a menor palaura q̃ se pode dar deshonesta" (id.) enquanto protegia a cristandade no Japão, passa a ser um homem cruel e mal educado que "respondendo con grande furia, disse que queria que se fossem todos os padres, \& que todos os que ficassem os mandaria matar, \& o mesmo faria com todos os que fossem a lapão daqui a diante, \& que nisto não averia nelle nenhum descuido, dizendo outras muitas palauras agastadas" (L. Fróis, 1589); "arrogante, \& soberbo" (id.), um "demonio... que pretende... aquirir... gloria, \& nome \& ser mais venerado do que nunca foi outro senhor em lapão. (...) homem mui sagaz, \& prudente secundum carnem, vai este tiranno encaminhandose pera ficar hum idolo, \& fazerse adorar pelo maior Cami [deus] que nunca ouue em lapão" (id.), além do que, "depois que se vio feito senhor da monarchia de lapão, \& confirmado \& seguro em seu estado (como outro Nero) descobrio muitos vicios que tinha ate então dissimulados, \& entre outros se entregou tão desenfreadamente ao vicio da sensualidade com molheres, que não lhe basta (conforme ao que se diz) ter juntas na sua fortaleza de Vóçaca perto de trezentas concubinas, alem da sua legitima \& principal molher, nem ter muitas em diuersas fortalezas" (L. Fróis, 1588)

O homem não consegue se desvencilhar das marcas da época, das circunstâncias em que vivem. Assim foi com a moral cristã eivada em todos 
os perfis que os portugueses dos séculos XVI e XVII traçaram dos japonesesda época. Isto se verifica, também, nas críticas que tecem sobre os expedientes de magia que os gentios usavam para curar doenças, expulsar "os demônios", citando, por outro lado, e com muito orgulho, os milagres alcançados pela reza e até mesmo com um pouco de água benta ou contas bentas. Acresce-se a isso, o empenho dos padres jesuítas em sua catequese, na necessidade de propalar nos meios europeus as conquistas que vinham obtendo. Não sem razão, vemos aquela gente prudente e "a melhor ategora descuberta" se transformar em cruéis e infiéis demônios, inimigos da Cristandade.

\section{NOTAS}

1. Há controvérsias sobre a exatidáo dessa data, bem como sobre chegadas anteriores dos portugueses ao Japåo.

2. As citaçőes das "Cartas" estáo apresentadas com o nome do autor e o ano de seu envio.

3. Retraduçáo minha, da tradução japonesa feita por A. Ebizawa da carta escrita por Xavier em Goa, em 1548, e que náo consta das "Cartas". 


\section{BIBLIOGRAFIA}

COMPANHIA DE JESUS. Cartas da India e Cartas de lapam (fac-símile do Tenri Centra Library). Tóquio, Yûshôdo, 1972.

BOXER, C.R. The Christian Century in Japan 1549-1650. Berkeley London, University of California Press, 1951.

EBIZAWA, A. Nihon kirishitanshi. Tóquio, Haniwa, 1969.

FROIS, L. Historia de Japam (edição anotada de José Wicki, S.J.). Lisboa, Biblioteca Nacional de Lisboa, 1976, 5 vs.

MATSUDA, K. Sei Francisco Xavier-no shôgai (tradução do original de J. Laures). Tóquio, Enderure, 1948.

et al. Nihon Junsatsuki - Valignano, in Tôyô Bunko, 229. Tóquio, Heibonsha, 1973. 